\title{
EU TOMO ANTIDEPRESSIVO, GRAÇAS A DEUS!
}

\section{ThanksGod I takean antidepressant!}

Moraes, C. (2008). Eu tomo antidepressivo, graças a Deus! Rio de Janeiro: BestSeller.

\author{
Luiz A. Vicente ${ }^{\mathrm{a}}$, Renate B. Vicente ${ }^{\mathrm{b}}$ \\ a Psicólogo, psicoterapeuta, mestrando em Saúde e Gestão do Trabalho pela UNIVALI, Itajaí, SC - Brasil, e-mail: \\ luizantoniovicente@ hotmail.com

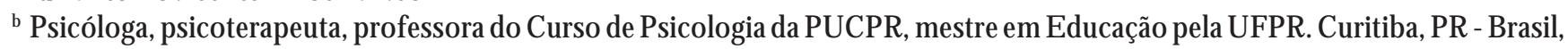 \\ e-mail: renate.vicente@ pucpr.br
}

Estabelecer o limite entre receitas de felicidade instantâneas, de resultados expressivamente limitados e efêmeros e a possibilidade de aliar experiências pessoais e de outros exemplos, a partir de depoimentos, de tratamentos de sucesso, ou não, tomam forma de maneira concisa e clara no que a autora se propõe quanto à desmistificação do tratamento psiquiátrico dos transtornos de humor ou afetivos.

Ao transitar entre o científico/ moderno e os exemplos próprios e de terceiros, estabelece um objetivo bem definido na sua concepção, em que pese os limites tênues entre um roteiro de autoajuda e um instrumento de orientação e de instigação à busca de tratamentos psiquiátricos e psicológicos. Alternando resumos de pesquisas bibliográficas, entrevistas com profissionais e na própria WEB, "contribui", uma jornalista de formação, para ampliar a discussão sobre as mais variadas formas de tratamento psiquiátrico dos referidos transtornos, referendando a utilização de medicamentos e a psicoterapia, concomitantemente, como imprescindíveis na condução terapêutica.

Quando indica, na Introdução/ apresentação do livro, a experiência pessoal como ponto de partida e, percebendo as dificuldades suas e de muitas outras pessoas quanto ao estigma/ preconceito com relação aos transtornos de humor, procura atribuir a necessidade, inicialmente, de um diagnóstico diferencial, específico e, mais do que isso, vencer o preconceito próprio e buscar ajuda. Nos oito capítulos que o compõe, a autora procura explorar, debater, indicar, sugerir processos de tratamento e, principalmente, como apresenta a obra, abordar um assunto marcado pelo estigma, pela rejeição e pelo silêncio.

No Capítulo I e II, propõe, de maneira sintética e didática, a responder dúvidas recorrentes sobre a Neurociência e a sintomatologia dos transtornos afetivos, utilizando-se de depoimentos de pacientes e profissionais da área da saúde, estabelecendo ligações entre as várias formas de tratamento 
e indicação de que o melhor caminho passa, necessariamente, pela combinação entre a medicação adequada e a psicoterapia.

Nos capítulos posteriores, leva os leitoresaum roteiro que envolvearevisão do surgimento e evolução dos medicamentos antidepressivos, as formas de ação, cuidados, interações medicamentosas e terapêuticas, procurando responder, segundo sua ótica, às perguntas mais comuns dos leitores leigos, cujas respostas podem indicar a necessidade de satisfação da curiosidade ou interesse pela busca por tratamentos.

Um capítulo especial, por assim dizer, 0 capítulo VI trata da importância da associação, nos transtornos afetivos, da psicoterapia e do tratamento medicamentoso como fundamentais e eficazes na ação sobre o problema. Entre um e o outro, colhe depoimentos, experiências de profissionais e indicações teóricas que respondem, de maneira não linear, determinista, a opção por ambos.

Nos capítulos posteriores, faz um breve histórico da evolução dos processos de tratamento dos transtornos afetivos, constatando o grande número de afastamentos do trabalho por problemas decorrentes de saúde mental, apontando, ainda, os aspectos da estigmatização do doente mental e as nuances sociais do processo de reforma psiquiátrica.

Mais do que um libelo a favor do consumo de medicamentos antidepressivos e, mesmo sendo escrito a partir de experiências pessoais por um autor sem uma formação específica na área da saúde, o resultado final acaba se tornando interessante tanto ao leigo quanto aos profissionais da saúde mental. Não constitui um manual ou roteiro predefinido de perguntas e respostas indicativas de formas de tratamentos pontuais, comerciais ou estanques. Ao contrário, provoca, instiga leigos e profissionais a abrir um processo de reflexão sobre as abordagens/ tratamentos dos transtornos mentais, sem enveredar por caminhos frágeis e fáceis, por mitos e estigmas que impedem uma atuação séria e responsável.

Recebido: 04/ 06/ 2008

Recived: 06/ 04/ 2008

Aprovado: 20/ 06/ 2008

Approved 06/20/ 2008 